Dwyer, J. W., Folts, W. E., \& Rosenberg, E. (1994). Caregiving in social context. Educational Gerontology, 20(7): 615-631. (Oct/Nov 1994) Published by Taylor \& Francis (ISSN: 0360-1277). Original version available at: http://www.tandf.co.uk/journals/UEDG

\title{
Caregiving in Social Context
}

\author{
Jeffrey W. Dwyer, W. Edward Folts, Edwin Rosenberg
}

\begin{abstract}
The heterogeneity of family caregiving is explored with specific emphasis on differences by gender, age, race, and area of residence. The aging of the population and other social structural changes during the next several decades will simultaneously increase the size of the population in need of long-term care and constrain the options available to frail elders and their care providers. Research suggests that there will be particularly deleterious consequences for women, older elders, nonwhites, and those who live in rural areas. In addition to these social characteristics, elder abuse and neglect, negative outcomes sometimes associated with caregiving, and the importance of linkages between formal and informal providers are discussed. Finally, the many contributions of older people to society and the fact that most elders are aging well are addressed. The modification of curricula to reflect caregiving in social context will enhance training programs designed for formal and informal providers who work with impaired elders and formal courses available to students in academic institutions. The latter represent future decision makers who will have the opportunity to influence public policies and intervention strategies whose benefits will redound to frail elders and their care providers.
\end{abstract}




\section{ARTICLE}

There are now more than 30 million people age 65 or older in the United States. That fact, combined with projections indicating that this number will more than double by 2060 (U.S. Bureau of the Census, 1989), has spurred debate about how private and public resources should be allocated to meet the needs of frail members of this population. Annual expenditures on institutional and in-home care for chronically impaired older adults total more than $\$ 100$ billion (Levit, Lazenby, Cowan, \& Letsch, 1991); however, 80\% of those who require long-term care are cared for in the community and receive most or all of their assistance from family members (Dwyer \& Coward, 1992; Scanlon, 1988). Hence, long-term care policy has relied on "free" care provided by family members.

This trend, along with long-term changes in social structure affecting both the availability of informal care providers and the normative obligation to provide caregiver support, means that current long-term care policy must either adapt or fail to meet the needs of a rapidly increasing number of older adults (Dwyer, in press; Goldscheider, 1990). Unfortunately, there are few signs that the current policy is adaptable or that policymakers are willing to address these issues comprehensively. The current draft of the Clinton health care reform plan, for example, provides for enhanced in-home care resources only after impairments in three activities of daily living (ADLs) are present. As most providers and caregivers know, substantial care is usually required well before this advanced level of frailty is documented.

The demography of caregiving indicates that providing care for older people has been a significant social issue for only the last quarter century. In 1900, there were only 3 million people over the age of 65 , the leading causes of death for elderly people were acute conditions such as influenza and pneumonia (Crandall, 1991), and the majority of middle-aged couples had no living parents (Uhlenberg, 1980). In contrast, there are 6--10 million functionally impaired older adults living in the community today (Coward, Cutler, \& Mullins, 1990; Macken, 1986); the leading causes of death are conditions such as heart disease and malignancies, typically preceded by long periods of chronic impairment (Crandall, 1991); and many people, even among those over the age of65, have living elderly parents (Coward, Horne, \& Dwyer, 1992).

Aging policy during the 20th century also suggests that the reliance on informal care providers as the primary source oflong-term care is a relatively recent phenomenon. At the beginning of the 20th century, in addition to being few in number and remaining relatively healthy until they died, older family members usually retained economic control of their holdings. Thus, physical or economic dependency was not normative (Haber, 1983). However, as industrialization increased during the early part of the 20th century, aging, and in some ways the elderly themselves, came to be perceived as a social problem. By the 1930s, old-age pensions were common, and support for the dependent aged was increasingly shifted to the public sector (Axinn \& Stern, 1985). Between 1930 and 1960, these changes had the effect of simultaneously relieving families of some caregiving responsibilities and driving the growth of a human services bureaucracy to meet the needs of the elderly population (Dwyer \& Coward, 1992; Fischer, 1978). 
The inability of the array of public programs initiated in the 1960s to provide adequately for older citizens, coupled with the economic decline of the 1970s and 1980s, converged to increase the use offamily care giving systems, on the basis of "the erroneous assumption that informal structures for providing care were underutilized and simply needed to be activated" (Hooyman, 1990, p. 223). At the same time, longer life expectancy and generally declining fertility rates have increased the likelihood of multigenerational family structures and reduced the number of family members in anyone generation. As Conner (1992) noted, "while the average number of horizontal relationships in the typical family has declined, the average number of vertical relationships has increased" (p. 105).

Changing social structure and the limitations of current public policy have particularly deleterious consequences for certain subsets of the older population. Moreover, the traditional educational approach, which views the older population as a homogeneous group lumped together under the convenient but overused label "the elderly," is no longer sufficient. Gerontologists' ability to design and implement policies and intervention strategies that will meet the needs of elders and their care providers into the 21st century is largely dependent on understanding the heterogeneity of the population and the unique needs of significant subgroups. The diversity of this population also requires that educators in gerontology make their students aware of the social characteristics that dramatically affect an individual's longterm care options.

Our purpose in this article is to explore the social context of family caregiving by focusing on four significant social characteristics: gender, age, race, and area of residence. Although the now voluminous caregiving literature provides important insights into these distinctions, our reviews are necessarily brief and intended simply to raise awareness of significant issues. We also discuss elder abuse and neglect as negative outcomes that sometimes result from caregiving situations and the importance of linkages between formal and informal care providers. Understanding these caregiving dimensions and issues may enhance gerontologists' ability to educate caregivers, providers, and students who may be involved as direct care providers; may influence public policies; and may contribute interventions targeted to specific types of frail elders and the individuals who care for them.

\section{GENDER}

It is now generally accepted that gender is one of the principal differentiating characteristics of the caregiving milieu. Most elderly people in need oflong-term care are women, and the majority of the caregiving assistance provided by families is provided by women. Because the caregiving burden is borne almost exclusively by women, intervention strategies and public policies should be targeted to their needs. 


\section{Older Adults}

Because women live longer and are less likely to suffer from fatal chronic conditions, most older adults who need long-term care are women (Lee, 1992; Verbrugge, 1989). In the general population over age 65, the ratio of women to men is 1.5 to 1 . However, among those age 65 or older who are impaired, the ratio of women to men is approximately 2 to 1 (Manton \& Soldo, 1985; Verbrugge, 1989). Women are more likely than men to be institutionalized CHing, 1987); to be cared for by an adult child rather than a spouse; and, when living in the community, to be unmarried and childless (Himes, 1992). Hence, women typically have fewer options for caregiving assistance. Goldscheider (1990) highlighted the gendered orientation of caregiving by arguing that among those who need caregiving assistance, "the poor and solitary are very likely to be women" (p. 535).

\section{Caregivers}

The likelihood of becoming a caregiver follows a hierarchical pattern with respect to the relationship ofthe caregiver to the care recipient: $A$ spouse is most likely to be the primary caregiver. In the absence of a spouse, adult children usually provide care, followed by other family members (e.g., siblings or grandchildren), and then neighbors and friends (Horowitz, 1985; Stoller, 1992). Yet within type of relationship, wives more often care for husbands than vice versa (Tennstedt, McKinlay, \& Sullivan, 1989), because women live longer and tend to marry men older than themselves; daughters are three times more likely than sons to provide care when other characteristics likely to affect caregiving behavior are controlled (Dwyer \& Coward, 1991); and sisters are more likely than brothers to provide care (Matthews \& Rosner, 1988). Indeed, in one study, $80 \%$ ofthe unmarried frail elderly living in the community were cared for by women (Soldo \& Myllyluoma, 1983).

The overwhelming reliance on women as the principal long-term care resource in the United States is problematic. From a structural perspective, the competing social demands that confront women (e.g" participation in the labor force and the economic consequences of divorce) will increasingly reduce their ability to provide the personal, intensive, and ongoing care often required by impaired older adults (Dwyer, in press). Future cohorts of women may also be less likely to adhere to the same filial norms and obligations as their predecessors. Finally, when men do participate in caregiving, they are more likely than women to be secondary, rather than primary, caregivers (Coward \& Dwyer, 1990); are less likely than women to be care providers and more likely to be care managers (Archbold, 1983); and are more likely than women to be backup or sporadic caregivers, to provide circumscribed care, or to provide no assistance at all (Matthews \& Rosner, 1988).

There is also an attitudinal/psychosocial dimension to caregiving that is gender specific. In analyzing results from the 1982 National Informal Caregivers Survey, Dwyer and Seccombe (1991) found that husbands reported more time spent caregiving and accomplishing more care

giving tasks than did wives. Similar reports by son and daughter caregivers were not statistically different. The authors explained these counterintuitive findings as probably due to the fact that 
men and women define the context of caregiving differently. The tasks usually associated with caregiving are those that have also traditionally been referred to as "women's work." Hence, when asked ifhe does the laundry or cooks as a result of his wife's disability, a husband is likely to respond in the affirmative. A wife, when asked the same question, typically responds in the negative, because these are tasks that she has always performed and have little to do with her spouse's disability.

\section{AGE}

Increased life expectancy and the dramatic growth in the older adult population that will occur during the next several decades underscore the need to focus on age differences as they relate to both the needs of care recipients and the responsibilities of care providers. The changes in the American age structure that will begin around 2005 as the baby boomers reach older ages are likely to have a profound impact on the types and amount of care that can be provided by the informal care system.

\section{Older Adults}

Whereas the population age 65 or older is projected to more than double by 2060 , the population age 85 or older will increase more than sixfold (to 18 million) during the same period (U.S. Bureau of the Census, 1989). This demographic "imperative," as it is sometimes called, is important because the oldest old (85+) are at much greater risk of being institutionalized than are younger cohorts of older adults (Rivlin, Wiener, Hanley, \& Spence, 1988). Furthermore, not only does the incidence of disabling chronic conditions increase with age (Verbrugge, 1989), but also the proportions of the population who are women and who are unmarried increase (National Research Council, 1988). Indeed, Himes (1992) has projected that by 2000 , approximately $20 \%$ of women over the age of 85 will be unmarried and childless. These women are at exceptionally high risk of needing some form of supportive care services. The fact that they lack the most common sources of caregiver support-spouses and adult children-implies that their only option may be some form of in-home or institutional care.

\section{Caregivers}

Because the caregiver's age reflects both the intensity of the care she or he provides and the difficulty of providing care, it is a critical variable in the study of elder care. As the age of an impaired older adult increases, the likelihood that the caregiver will be a nonspouse relative also increases (Dwyer \& Coward, 1992). There is also a greater likelihood that the caregiver will be an older adult caring for a parent or parent-in-law (Coward, Cutler, \& Schmidt, 1989). Furthermore, unique to the coming decades is the chilling prospect that more older caregivers will be called on to provide care simultaneously to both a frail spouse and an increasingly dependent parent. Moreover, many will spend more years providing care to elderly relatives 
than to children (Older Women's League, 1989; Stone, Cafferata, \& Sangl, 1987). As greater numbers of adult children, primarily daughters, become caregivers as a result of the aging of the population, the impact of competing demands will become even more important. By 2000 , for example, it is projected that $76.5 \%$ of women ages $45-54$ and $49 \%$ of women ages $55-64$ will be in the full-time labor force (Shank, 1988).

\section{RACE}

The number of older Mrican Americans doubled between 1960 and 1990 from 1.2 million to 2.6 million. In part as a result of better health care and attendant increases in life expectancy, the number of elderly people of color is projected to triple to 7.8 million by 2030 (Angel \& Hogan, 1991). Long-term care policies have never adequately addressed minority issues. The magnitude of the projected increase in the size of this population is likely to exacerbate an already difficult problem.

\section{Older Adults}

Older adults of color are more likely than older white adults to experience chronic disabilities (Markides \& Mindel, 1987), yet they are less likely than older whites to be institutionalized (Dwyer, Barton, \& Vogel, 1994; Greene \& andrich, 1990). Specifically, older African Americans are about half as likely as whites to use long-term care institutions (Crystal, 1982). The expected growth of the minority elderly population, coupled with characteristically poorer health and higher rates of poverty (Chen, 1991), places them at increased risk of not receiving the long-term care services they require. In addition, projections indicate that older African American women are more likely than older white women to be without a spouse and children as their age and need for long-term care assistance increase (Himes, 1992).

\section{Caregivers}

The limited use of long-term care institutions by minorities, particularly by African American elders, has frequently been tied to stronger familial support networks (Crystal, 1982). Yet evidence suggests that older adults of color are no more likely to receive assistance from their children (Mindel, Wright, \& Starrett, 1986) or to live in a shared household with kin (Soldo, Wolf, \& Agree, 1990) than are other segments of the older population. What this means, of course, is that the incorrect but general perception that minority families are more likely to "take care of their own" is especially harmful. Because older adults of color are underrepresented in longterm care institutions and are no more likely to receive certain forms of informal family care than other segments of the older population, many of them must fend for themselves. Present longterm care policies that depend on informal caregivers to meet the needs of minority elders are based on incorrect assumptions and must be reassessed in the near future. 


\section{AREA OF RESIDENCE}

\section{Older Adults}

Approximately one fourth of all older adults in the United States live in nonmetropolitan areas (U.S. Senate, Special Committee on Aging, 1992). Although most differences in health status between rural and urban elders disappear when other population characteristics are controlled (Cutler \& Coward, 1988), disparities in the availability, awareness, and use of formal services persist (Dwyer, Lee, \& Coward, 1991). For example, older adults living in rural areas are less likely than those living in urban areas to participate in health promotion activities (Lubben, Weiler, Chi, \& DeJong, 1988), to benefit from Title XX social service dollars (Nelson, 1983), and to have access to programs and services designed to meet the needs ofthe most severely impaired older adults (Sharp, Halpert, \& Breytspraak, 1988). As a result, rural elders are at risk of entering nursing homes at younger ages and in better health than their urban counterparts (Dwyer et al., 1994; Greene, 1984).

\section{Caregivers}

Rural elders are also more likely than urban elders to live with a spouse (Coward et al., 1989), to have living children (Lee, Dwyer, \& Coward, 1990), and to have family members available to provide assistance. Although research from the last decade reveals that rural elders are no more likely than urban elders to be embedded in supportive social networks (Dwyer et al., 1991), the helping networks of the rural elderly are more likely to consist exclusively of informal sources of support (Blieszner, McCauley, Newhouse, \& Mancini, 1987). Related research also indicates that characteristics of care giving situations have differential effects across residential categories (i.e., rural, small city, and urban area) in terms of the stress and burdens placed on primary caregivers (Dwyer \& Miller, 1990). Caregivers in rural categories consistently report more stress, more burden, and less external assistance than do caregivers in urban areas.

\section{ELDER ABUSE AND NEGLECT}

Because we choose our friends but not our family, because perceived obligations to family members are at least as strong as those to our friends, and because the family is such an emotionally bonded primary group, it is inevitable that taking on a caregiving role for a dependent elder can create or add to strain in numerous ways. Elder abuse and neglect can be unfortunate outcomes of such intrafamilial strain. Research has identified abuse and neglect risk factors for caregivers, care recipients, and the family system. In general, the lack of anticipation or preparation by any or all parties increases the odds of strain and, thus, abuse (Steinmetz, 1988), as do emotional problems that negatively affect interpersonal relationships (Godkin, Wolf, \& Pillemer, 1989). Family system risk indicators include financial strain, marital problems, and lack of family support for caregiving (Kosberg, 1988). Finally, recipient traits are less powerful predictors of abuse and neglect than are caregiver traits (Pillemer \& Finkelhor, 1989). 


\section{Older Adults}

For the elderly care recipient, risk factors typically mentioned include being female, being of advanced age, and having alcohol problems (Kosberg, 1988; Steinmetz, 1988). But identification of risk factors remains inconclusive. For example, whereas some researchers have linked abuse and neglect risk to higher levels of dependency or multiple demands (Kosberg, 1988; Steinmetz, 1988), others have found that increased needs are not significantly related to the likelihood of abuse (Godkin et al., 1989; Pillemer \& Finkelhor, 1989). In addition, Finkelhor and Pillemer (1988) have reported that whereas abuse of older women was more severe, older men were more likely to be abuse victims. Finally, Pillemer (1985), using samples of abused and nonabused elderly matched for gender and living arrangement, found that abused older persons were younger, less impaired physically, and less dependent physically and economically than nonabused older persons.

\section{Caregivers}

Caregivers who abuse or neglect their charges are more likely to have a substance abuse problem or other "deviant" traits, be inexperienced in the caregiving role, have financial problems, be highly dependent (e.g., financially) on the care recipient, and be subjected to constant criticisms (Godkin et al., 1989; Kosberg, 1988; Pillemer \& Finkelhor, 1989; Steinmetz, 1988). Spouses and sons are more likely than daughters to abuse (Finkelhor \& Pillemer, 1988). The application of this knowledge has lagged far behind other efforts to address the needs of caregivers and their frail older relatives. Beyond a recognition that caregiver stress may be an important contributing factor in cases of elder abuse, few interventions based on this knowledge have been attempted.

\section{LINKING FORMAL AND INFORMAL CAREGIVING}

A review of caregiving in social context cannot ignore the actual and potential linkages between the family (or other caregiving) unit and the formal caregiving system. The investigation of such linkages must examine both structure and process, because each has an impact on outcomes. Noelker and Bass (1989), studying personal care and home health services for persons age 60 or older, identified four categories of the intermingling (or lack thereof) of family caregivers and service agencies: kin independence, formal service specialization, dual specialization, and supplementation. The family-agency relationship is shaped by the caregiver's and care recipient's needs, family history, family resources, and service provider availability. Further evidence of the real and perceived benefits of informal-formal caregiving linkages was provided by a survey of 76 local agency administrators (Linsk, Osterbusch, Simon-Rusinowitz, \& Keigher, 1988). Fifty-six percent of the respondents either found it cost-effective to hire family members as caregivers or said they would hire family members if sufficient resources were available.

Another argument for formal-informal linkages and for flexibility of care arrangements stems from findings that the quality of the relationship between the caregiver and care recipient is 
highly predictive of the care recipient's level of satisfaction. This finding holds regardless of the recipient's level of functioning (Parsons, Cox, \& Kimboko, 1989). While family members are usually the recipient's first choice to be caregivers, good relations-and thus high satisfaction-are not restricted to family. Comparing hospital patients discharged to nursing homes with those discharged to foster homes, Oktay, Horwitz, and Volland (1988) found that the latter scored higher on functional measures and nursing goals. They also found foster home caregivers to be actively interested in the aged, happy to be able to work at home, and desirous of delaying or preventing institutionalization of the care recipient.

\section{MEASURING AND PREDICTING QUALITY OF CAREGIVING}

The increase in research on factors linked to successful and problematic caregiving suggests the development of instruments that can predict caregiving obstacles for caregivers, care recipients, and families. If such instruments can be validated through careful testing, the information they yield should allow a more effective use of resources to assist potentially dysfunctional caregiving arrangements. In the caregiving environment, prevention is preferable to intervention. Two examples of this are the Beliefs About Caregiving Scale (Phillips, Rempusheski, \& Morrison, 1989) and the QUAL CARE Scale (Phillips, Morrison, \& Chae, 1990a, 1990b). The former, tested in four studies, focuses on identifying caregivers likely to provide low-quality care to a dependent older person. The QUAL CARE Scale, tested on nearly 250 caregiver-recipient pairs, evaluates the quality of care provided by family members to older persons. Physical, medical, financial, psychosocial, human rights, and environmental dimensions are included.

As caregiving patterns and issues continue to be described in increasing breadth and depth, there is no reason why research cannot simultaneously move toward testing and validation of measures of caregiving quality. The transformation of findings into applied tools will be of great use to the growing numbers of caregivers, care recipients, and related helping professionals.

\section{FUTURE RESEARCH NEEDS}

Despite the large and growing literature on caregiving, there are several areas in which our present understanding remains limited. This section identifies four areas of research that could yield better information than is currently available to formal care providers, policymakers, informal caregivers, and older adults.

First, more research is needed that highlights the heterogeneity of caregiving situations and relationships. For example, although research typically focuses on the impaired and frail elderly, more emphasis should be placed on understanding those tasks that even disabled elders can perform. Some recent research has indicated that the well-being of older adults as well as the stress and burden associated with caregiving may be influenced directly or indirectly by the degree of the older person's reciprocity in the care giving context (Dwyer, Lee, \& Jankowski, 1994). To put it simply, those older adults who are perceived as helpful produce a care giving 
experience that is less stressful for the caregiver, resulting in better care. More attention should also be given to the heterogeneity of the older population, including interactions between two or more social characteristics. For example, rural African Americans appear to be especially at risk of not having access to institutional care (Dwyer et al., 1994), and older African American women are at greatest risk of having neither a spouse nor a child as a care giving resource in old age (Himes, 1992). The size of certain subgroups within the older population, even when cross-classified by indicators such as gender and residence or gender and race, is sufficient to warrant the use of appropriate research techniques as well as policies targeted for their benefit.

A related concept that deserves further exploration, especially in view of the traits and situations of older persons, is fictive kin. Scott and Black (1989) suggested that the study of the African American family has been hampered by the historical use of the Anglo family structure as a frame of reference. They then argued for the recognition of fictive kin as an element of the kinship structure of the Mrican American family; the tendency is to develop fictive family relationships in new situations and to create fictive kin when there are no relatives. In a study of older African Americans and whites, Johnson and Barer (1990) found a propensity among African Americans to use fictive kin to expand their family networks. African Americans were also more likely than whites to rely on their church to relieve social isolation, and to have contact with their relative and friend networks. Fruitful findings could emerge from further study of the reasons behind and functions of fictive kin.

Third, a glaring deficiency in the caregiving literature is the focus on proximal events to the near exclusion of distal events. Because the effects on caregiving situations oftransitions and events that occurred earlier in both elders' and the caregivers' lives have not been explored, a great deal of understanding regarding the caregiving milieu has been missed. Bedford (1992) found, for example, that memories of being the least favored child affected the quality ofthe parentchild bond in later life. Preliminary results from a more recent study indicate that early life separations from parents affect the later life caregiving behaviors of adult children (Dwyer \& Henretta, no date). Goldscheider (1990) has also argued that early life separations due to divorce may reduce the normative obligation to provide care to the separated parent (usually the father) later in life. Greater understanding offamily history factors that may influence the initiation, quality, and quantity of care would be useful.

Finally, caregiving relationships and situations should be viewed as fluid rather than static. Although Stone et al. (1987) reported that a large number of caregivers in the 1982 Informal Caregivers Survey had provided care for more than 6 years, more recent findings suggest that, among adult children, caregiving is much more sporadic. Dwyer, Henretta, Coward, and Barton (1992) reported that $50.7 \%$ of sons and $29.9 \%$ of daughters who were providing care at baseline were no longer doing so 2 years later. Moreover, even after a number of variables likely to influence the provision of care were controlled, daughters were more likely than sons to sustain caregiving over the 2-year period. Having an understanding of the dynamic nature of the caregiving environment will help gerontologists provide policymakers with more accurate assessments ofthe potential effectiveness of policies designed to support the provision of longterm care by family members. 
The social context of caregiving requires that educators understand the interconnectedness of the issues involved. If the veritable explosion of gerontological research on caregiving experienced in the last decade appears somewhat unfocused and confusing, one thing remains clear: Neither caregiving nor its impact on the lives of those who provide it and those who receive it can be considered outside ofthe social context within which it is expressed.

Gerontological educators have a long history of concerning themselves with debunking the myths and stereotypes associated with aging. To accomplish this, they have often found it necessary to approach aging as an event that can be isolated from other personalized events. In light of the challenges, problems, and opportunities that will be present in the 21st century, educators would be wise to reinvent an orientation that recognizes the particular social context within which people are born, age, and die.

\section{REFERENCES}

Angel, J. L., \& Hogan, D. P. (1991). The demography of minority aging populations. In Task Force on Minority Issues (Ed.) Minority elders: Longevity, economics, and health (pp. 1-13). Washington, DC: Gerontological Society of America.

Archbold, P. G. (1983). Impact of parent-caring on women. Family Relations, 32,39-45.

Axinn, J., \& Stern, M. J. (1985). Age and dependency: Children and the aged in American social policy. Milbank Memorial Fund Quarterly, 63, 648-670.

Bedford, v. H. (1992). Memories of parental favoritism and the quality of parent-child ties in adulthood. Journal of Gerontology: Social Sciences, 47, 149-155.

Blieszner, R., McCauley, W. J., Newhouse, J. K, \& Mancini, J. A. (1987). Rural-urban differences in service use by older adults. In T. H. Brubaker (Ed.), Aging, health, and family (pp. 162-174). Newbury Park, CA: Sage.

Chen, Y. P. (1991). Improving the economic security of minority persons as they enter old age. In Task Force on Minority Issues (Ed.), Minority elders: Longevity, economics, and health (pp. 14-23). Washington, DC: Gerontological Society of America.

Conner, K A. (1992). Aging America: Issues facing an aging society. Englewood Cliffs, NJ: Prentice Hall.

Coward, R. T., Cutler, S. J., \& Mullins, R. A. (1990). Residential differences in the helping networks of impaired elders. Family Relations, 39, 44--50.

Coward, R. T., Cutler, S. J., \& Schmidt, F. E. (1989). Differences in the household composition of elders by age, gender, and area of residence. The Gerontologist, 26, 814-821.

Coward, R. T., \& Dwyer, J. W. (1990). The association of gender, sibling network composition, and patterns of parent care by adult children. Research on Aging, 12, 158-181. 
Coward, R. T., Horne, C., \& Dwyer, J. W. (1992). Demographic perspectives on gender and family caregiving. In J. W. Dwyer \& R. T. Coward (Eds.), Gen. der, families and elder care (pp. 18-33). Newbury Park, CA: Sage.

Crandall, R. C. (1991). Gerontology: A behavioral science approach (2nd ed.). New York: McGraw-Hill.

Crystal, S. (1982). America's old age crisis. New York: Basic Books.

Cutler, S. J., \& Coward, R. T. (1988). Residence differences in the health status of elders. Journal of Rural Health, 4, 11-26.

Dwyer, J. W. (in press). The effects of illness on the family. In R. Blieszner \& V. H. Bedford (Eds.), Handbook on aging and the family. New York: Greenwood Press.

Dwyer, J. W., Barton, A J., \& Vogel, W. B. (1994). Area of residence and the risk of institutionalization. Journal of Gerontology: Social Sciences, 49, 575-584.

Dwyer, J. W., \& Coward, R. T. (1991). A multivariate comparison of the involvement of adult sons versus daughters in the care of impaired parents. Journal of Gerontology: Social Sciences, 46, S259-S269.

Dwyer, J. W., \& Coward, R. T. (1992). Gender, families, and elder care. Newbury Park, CA: Sage.

Dwyer, J. W., \& Henretta, J. C. (no date). The impact of early life course transitions on long-term care outcomes. Unpublished manuscript.

Dwyer, J. W., Henretta, J. C., Coward, R. T., \& Barton, A J. (1992). Determinants of changes in the helping behaviors of adult children as caregivers. Research on Aging, 14, 351-375.

Dwyer, J. W., Lee, G. R., \& Coward, R. T. (1991). The health status, health services utilization, and support networks of the rural elderly: A decade review. Journal of Rural Health, 6, 379-397.

Dwyer, J. W., Lee, G. R., \& Jankowski, T. B. (1994). Reciprocity, elder satisfaction, and caregiver stress and burden: The exchange of aid in the family caregiving relationship. Journal of Marriage and the Family, 56, 35--43.

Dwyer, J. W., \& Miller, M. K. (1990). Differences in characteristics of the caregiving network by area of residence: Implications for primary caregiver stress and burden. Family Relations, 39, 27-37.

Dwyer, J. W., \& Seccombe, K. (1991). Elder care as family labor: The influence of gender and family position. Journal of Family Issues, 12, 229-247.

Finkelhor, D., \& Pillemer, K. (1988). The prevalence of elder abuse: A random sample survey. The Gerontologist, 28, 51-57.

Fischer, D. H. (1978). Growing old in America. New York: Oxford University Press. 
Godkin, M. A, Wolf, R. S., \& Pillemer, K. A (1989). A case-comparison analysis of elder abuse and neglect. International Journal of Aging and Human Development, 28, 207-225.

Goldscheider, F. K. (1990). The aging of the gender revolution. Research on Aging, 12, 531545.

Greene, V. L. (1984). Premature institutionalization among the rural elderly in Arizona. Public Rural Health, 99, 58-63.

Greene, V. L., \& Ondrich, J. I. (1990). Risk factors for nursing home admissions and exits: A discrete-time hazard function approach. Journal of Gerontology: Social Sciences, 45, S250S258.

Haber, C. (1983). Beyond sixty-five: The dilemma of old age in America's past. New York: Cambridge University Press.

Himes, C. L. (1992). Future caregivers: Projected family structures of older persons. Journal of Gerontology: Social Sciences, 17, SI7-S26.

Hing, E. (1987). Use of nursing homes by the elderly: Preliminary data from the 1985 National Nursing Home Survey (Vital and Health Statistics Advance Data No. 135). Hyattsville, MD: National Center for Health Statistics.

Hooyman, N. (1990). Women as caregivers to the elderly. In D. E. Biegel \& A. Blum (Eds.), Aging and caregiving: Theory, research, and policy (pp. 221- 241). Newbury Park, CA: Sage.

Johnson, C. L., \& Barer, B. M. (1990). Families and networks among older inner-city Blacks. The Gerontologist, 30, 726-733.

Kosberg, J. 1. (1988). Preventing elder abuse: Identification of high risk factors prior to placement decisions. The Gerontologist, 28, 43-50.

Lee, G. R. (1992). Gender differences in family caregiving: A fact in search of a theory. In J. W. Dwyer \& R T. Coward (Eds.), Gender, families, and elder care (pp. 120-131). Newbury Park, CA: Sage.

Lee, G. R, Dwyer, J. W., \& Coward, R T. (1990). Residential location and proximity to children among impaired elder parents. Rural Sociology, 55, 579-589.

Levit, K R, Lazenby, H. C., Cowan, C. A., \& Letsch, S. W. (1991). National health expenditures, 1990. Health Care Financing Review, 13, 29-54.

Linsk, N. L., Osterbusch, S. E., Simon-Rusinowitz, L., \& Keigher, S. M. (1988). Community agency support of family caregiving. Health and Social Work, 13, 209-218.

Lubben, J. E., Weiler, P. G., Chi, 1., \& DeJong, F. (1988). Health promotion for the rural elderly. Journal of Rural Health, 4, 85-96. 
Macken, C. L. (1986). A profile offunctionally impaired elderly persons living in the community. Health Care Financing Review, 7, 33-49.

Manton, K, \& Soldo, B. (1985). Dynamics of health changes in the oldest old: New perspectives and evidence. Milbank Memorial Fund Quarterly, 63, 206-285.

Markides, K S., \& Mindel, C. H. (1987). Aging and ethnicity. Newbury Park, CA: Sage.

Matthews, S. H., \& Rosner, T. T. (1988). Shared filial responsibility: The family as the primary caregiver. Journal of Marriage and the Family, 50, 185-195.

Mindel, C. H., Wright, R, \& Starrett, R (1986). Informal and formal social and health service use by black and white elderly: A comparative cost approach. The Gerontologist, 26, 279-285.

National Research Council. (1988). The aging in the twenty-first century. Washington, DC: National Academy Press.

Nelson, G. M. (1983). A comparison of Title XX services to the urban and rural elderly. Journal of Gerontological Social Work, 6, 3-23.

Noelker, L. S., \& Bass, D. H. (1989). Home care for elderly persons: Linkages between formal and informal caregivers. Journals of Gerontology, 44, 563- 570.

Older Women's League. (1989). Failing America's caregivers. Washington, DC: Author.

Oktay, J., Horwitz, K., \& Volland, P. J. (1988). Evaluation ofthe quality of care and the cost ofthe Community Care Program. Adult Foster Care Journal, 2, 52-71.

Parsons, R. J., Cox, E. 0., \& Kimboko, P. J. (1989). Satisfaction, communication and affection in caregiving: A view from the elder's perspective. Journal of Gerontological Social Work, 13, 9-20.

Phillips, L. R., Morrison, E. F., \& Chae, Y. M. (1990a). The QUALCARE scale: Developing an instrument to measure quality of home care. International Journal of Nursing Studies, 27, 61-75.

Phillips, L. R., Morrison, E. F., \& Chae, Y. M. (1990b). The QUALCARE scale: Testing of a measurement instrument for clinical practice. International Journal of Nursing Studies, 27, 7791.

Phillips, L. R., Rempusheski, V. F., \& Morrison, E. (1989). Developing and testing the Beliefs About Caregiving Scale. Research in Nursing and Health, 12, 207-220.

Pillemer, K. (1985, August). The dangers of dependency: New findings on domestic violence against the elderly. Paper presented at the annual meeting of the American Sociological Association, Washington, DC.

Pillemer, K., \& Finkelhor, D. (1989). Caregiver stress versus problem relatives. American Journal of Orthopsychiatry, 59, 179-187. 
Rivlin, A. M., Wiener, J. M., Hanley, R. J., \& Spence, D. A. (1988). Caring for the disabled elderly: Who will pay? Washington, DC: Brookings Institution.

Scanlon, W. J. (1988). A perspective on long-term care for the elderly. Health Care Financing Review, 10 (Annual Suppl.), 7-15.

Scott, J. W., \& Black, A. (1989). Deep structures of Mrican American family life: Female and male kin networks. Western Journal of Black Studies, 13, 17-24.

Shank, S. E. (1988). Women and the labor market: The links grow stronger. Monthly Labor Review, 3, 3-8.

Sharp, T. S., Halpert, B. P., \& Breytspraak, L. M. (1988). Impact of Medicare's prospective payment system and the farm crisis on the health care of the elderly: A case study. Journal of Rural Health, 4, 45-56.

Soldo, B., Wolf, D., \& Agree, E. (1990). Family, households and care arrangements of frail older women: A structural analysis. Journal of Gerontology: Social Sciences, 45, S238-S249.

Soldo, B., \& Myllyluoma, J. (1983). Caregivers who live with dependent elderly. The Gerontologist, 23, 605-611.

Steinmetz, S. K. (1988). Elder abuse by family caregivers: Processes and intervention strategies. Contemporary Family Therapy, 10, 256-271.

Stoller, E. P. (1992). Gender differences in the experiences of care giving spouses. In J. W. Dwyer \& R. T. Coward (Eds.), Gender, families, and elder care (pp. 49-64). Newbury Park, CA: Sage.

Stone, R. Cafferata, G. L., \& Sangl, J. (1987). Caregivers ofthe frail elderly: A national profile. The Gerontologist, 27, 616-626.

Tennstedt, S., McKinlay, J., \& Sullivan, L. M. (1989). Informal care for frail elders: The role of secondary caregivers. The Gerontologist, 29, 677-683.

Uhlenberg, P. (1980). Death and the family. Journal of Family History, 5, 313-320.

U.S. Bureau ofthe Census. (1989). Projections of the population of the United States by age, sex, and race (Current Population Reports, Series P-25, No. 1018). Washington, DC: U.S. Government Printing Office.

U.S. Senate, Special Committee on Aging. (1992). Common beliefs about the rural elderly: Myth or fact? Washington, DC: U.S. Government Printing Office.

Verbrugge, L. M. (1989). Gender, aging, and health. In K. S. Markides (Ed.), Aging and health (pp. 23-78). Newbury Park, CA: Sage. 